\title{
PREPARATION OF ULTRA-LOW VOLUME WEIGHT AUTOCLAVED AERATED CONCRETE
}

\author{
\#ONDŘEJ KOUTNÝ, JIŘÍ KRATOCHVÍL, TOMÁŠ OPRAVIL \\ Faculty of Chemistry, Brno University of Technology, Purkyňova 118, 61200 Brno, Czech republic \\ "E-mail: Ondrej.Koutny@vut.cz
}

Submitted March 31, 2016; accepted October 24, 2016

\begin{abstract}
Keywords: Aerated concrete, Foam stability, Optimization, Low volume weight
Autoclaved aerated concrete is a modern construction material that gains its popularity especially due to its thermal insulation performance resulting from low volume weight and porous structure with sufficient mechanical strength. Nowadays, there are attempts to use this material for thermal insulation purposes and to replace current systems, which have many disadvantages, mainly concerning durability. The key for improvement of thermal insulation properties is therefore obtaining a material based on autoclaved aerated concrete with extremely low volume weight (below $200 \mathrm{~kg} \cdot \mathrm{m}^{-3}$ ) ensuring good thermal isolation properties, but with sufficient mechanical properties to allow easy manipulation. This material can be prepared by foaming very fine powder materials such as silica fume or very finely ground sand. This paper deals with the possibilities of preparation and summarizes the basic requirements for successful preparation of such a material.
\end{abstract}

\section{INTRODUCTION}

Autoclaved aerated concrete (AAC) is an inorganic material characterized by very low heat conductivity due to its porous structure. At the same time it has sufficient mechanical strength, which enables using ordinary AAC in the field of civil engineering as a masonry loadbearing element. Commonly produced AAC is manufactured by autoclaving of fully-foamed and partially hydrated mixture of siliceous materials such as ground quartz sand or fly ash, Portland cement (with high initial strength), quicklime, gypsum and water with addition of small amount of aluminium powder as a foaming agent. Foaming is caused by the generation of hydrogen which is the product of the reaction between fine aluminium powder and water in highly alkaline solutions with $\mathrm{pH}$ above 12 due to Portland cement hydration [1-3]. The released gas drifts up the fine mixture and creates a cellular structure which is mainly stabilized due to the fast hydration and partial setting of the binders used. Within approximately 15 minutes (depending on precuring temperature) after mixing the aluminium powder is completely reacted and a large amount of hydrogen is released causing approximately 200 - $500 \%$ volume expansion and the formation of a porous structure $[1,3,4]$. This structure is primarily responsible for the final heat conductivity due to high volume of entrapped air which significantly decreasing the heat conductivity coefficient $\lambda$ of the bulk material. After several hours the partially hydrated body is cured in autoclave for approximately 15 hours at $174-193^{\circ} \mathrm{C}$ using saturated steam at the appropriate pressure. From technological point of view these temperatures are optimal for tobermorite formation [1, 5-7]. The hydrothermal conditions providing by the autoclave enable the formation of several minerals based on calcium hydrosilicates. The highest priority belongs to $11 \AA$ tobermorite, which is the main mineral structure responsible for the final mechanical properties [6-9]. Today the civil engineering attention is focussed especially on systems which effectively reduce energy consumption and decrease costs associated with using of residential or industrial objects. According to this statement AAC with substantially increased thermal insulating properties, realized by minimizing of volume weight, seems to be a solution. The use of this material for thermal insulation purposes seems to be a fullyfledged alternative to standard thermal insulation systems also due to combination of water vapour permeability, sufficient strength, durability and non-flammability.

The objective of the present study is to design and successfully prepare a material based on AAC with very low volume weight and sufficient compressive strength for which a very low thermal conductivity can be expected. The preparation of such a material will follow standard technology guidelines of AAC in Europe for easy implementation of the results into real production technology. Utilization of this material could be found in the production of thermal insulation panels. In contrast to ordinary AAC, the material presented in this study is not designed for load-bearing members. 


\section{THEORETICAL}

The main key to achieve better thermal insulation properties is minimizing the volume weight, which results in a larger amount of entrapped air and a more porous structure. This is the main parameter affecting the heatconductivity. From previous studies and experiences in the field of AAC it can be concluded that the volume weight can be significantly decreased by increasing the total surface area of the material mixture without increasing the dosage of foaming agent $[3,4]$. Due to the higher specific surface area of raw materials (smaller particles) higher surface energy can be expected. Therefore, a large amount of released hydrogen and entrapped air can be adsorbed on individual solid particles which can be easily transported through the volume of fresh material. This effect can be mainly achieved by finer grinding of sand and using very fine powders like silica fume (SF), which has also a positive effect on tobermorite formation [10]. Unfortunately, due to the addition of fine spherical hydrophilic particles, like SF, a significant destabilization followed by coalescence of the foamed structure occurs. The reason why this effect is observed is the hydrophilic character of the raw material particles. It is well known that, together with transport of particle to the gas-liquid interface, the overall Gibbs free energy of the system is reduced, resulting in a more favourable thermodynamic conditions. The energy is consumed due to the adsorption processes. The energy reduction at a flat interface can be mathematically described by Equation 1 [11]:

$$
\Delta G_{a d s}=\pi D_{p}^{2} \gamma(1 \pm \cos \theta)^{2},
$$

where $\gamma$ is the surface energy of gas-liquid interface, $D_{p}$ is the particle diameter and $\theta$ is the contact angle. Nevertheless, value of $\Delta G_{\text {ads }}$ cannot be used individually as an evaluation criterion of interface stability. The argument can be used only for comparing the energy released due to adsorption of solid particles, characterized by its own thermal energy, which is the consequence of Brownian motion in the suspension. When the value of particle thermal energy is close to the particle adsorption energy, an instability of particles on the gas-liquid interface will be observed that leads to destabilization of the interface. The degree of interface stability can be described by Equation 2 [12]:

$$
\text { Interface stability }=\frac{\Delta G_{a d s}}{k_{B} T}=\frac{\text { Adsorption energy }}{\text { Thermal energy }},
$$

where the particle thermal energy is defined by $k_{B} T$, where $k_{B}$ is the Boltzmann constant and $T$ the thermodynamic temperature [11]. The value $k_{B} T$ can therefore be considered as a parameter affecting the stability of the gasliquid interface with adsorbed particles. This parameter enables to evaluate the stability of different foams formed by solid particles according to its particle size, wettability and foaming temperature. In the case of foam stability the adsorption and thermal energy ratio represents the main evaluation criterion. From previous experimental results it can be concluded that in the case of silica fume suspensions the stabilization effect occurs when the adsorption energy is by three orders of magnitude higher than the thermal energy [11]. Unfortunately, these foams have naturally very low stability. The reason why the foams created by inorganic hydrophilic fine particles are unstable can be found in the values of its adsorption and thermal energy which are in the most cases comparable $[11,13]$.

In $\mathrm{AAC}$ technology it is necessary to work at relatively high temperatures (around $50-70^{\circ} \mathrm{C}$ for a steady release of hydrogen) and with very fine materials to achieve a highly porous structure with low volume weight and therefore low thermal conductivity. The only way how to solve this problem in AAC technology is to reduce the particle affinity to water, i.e. the contact angle $\theta$, by selecting appropriate admixtures. An inspiration can be found in flotation devices where the separation of solids is realized by the formation of stable foam. Stability of foam is achieved by the adsorption of watersoluble amphiphilic organic molecules with hydrophilic functional group and hydrophobic carbon chain. Monocarboxylic acids, $\alpha$-substituted dicarboxylic acids, carboxylic acid derivatives (amides, esters) or primary amines can be classified in this category. When water is expelled from the gas-solid interface, compaction of solids occurs in the suspension film between pores. Therefore, foam stability satisfactorily increases $[14,15]$. From empirical investigation, all fresh foams for the production of AAC with volume weight under $180 \mathrm{~kg} \mathrm{~m}^{-3}$ are highly unstable without any external stabilization system.

A mutual comparison via mechanical efficiency $(M E)$ of AAC-based materials is mainly realized by comparing the compressive strength $R_{p}$ and volume weight $\rho$ according to Equation 3 [16]:

$$
M E=\frac{R_{p}}{\rho^{2} \cdot 0.016} \frac{[\mathrm{Pa}]}{\left[\mathrm{kg}^{2} \mathrm{~m}^{-6}\right]} .
$$

An empirical factor 0.016 has its origin in longterm monitoring of compressive strength and volume weight realized by producers. In general, the higher $M E$, the better the mechanical quality of the AAC product. For present-day products the $M E$ value for heat-insulating load-bearing products reaches approximately $1500 \mathrm{~Pa} \cdot \mathrm{kg}^{-2} \cdot \mathrm{m}^{6}$.

\section{EXPERIMENTAL}

In our previous study [17] we investigated the influence of a substitution of ground quartz sand (S) by silica fume (SF) and the influence of specific surface $s_{\mathrm{s}}$ of $\mathrm{S}$ used in the standard mixture mentioned above. Our goal was to prepare a material with final volume weight of approximately $120 \mathrm{~kg} \cdot \mathrm{m}^{-3}$ which was successful. Some basic characteristics of this material are summarized in Table 1 . 
Table 1. Properties of final samples from study [17].

\begin{tabular}{cccc}
\hline $\mathrm{SF} / \mathrm{S}$ & $s_{s}\left[\mathrm{~m}^{2} \cdot \mathrm{kg}^{-1}\right]$ & $\rho\left[\mathrm{kg} \cdot \mathrm{m}^{-3}\right]$ & $R_{p}[\mathrm{MPa}]$ \\
\hline $30 \%$ & 630 & 125.9 & 0.35 \\
\hline
\end{tabular}

The aim of the present investigation and methodology setup follows our published results presented in [17]. Therefore, the experimental data from that study are not repeated in the present paper. The primary goal of this paper is to optimize our already modified recipe containing $\mathrm{S}$ with optimum fineness and optimum addition of SF to minimize volume weight and maximize $M E$. Unfortunately, the compressive strength of the prepared samples is not fully satisfactory for maintaining self-stability $\left(M E=1380 \mathrm{~Pa} \cdot \mathrm{kg}^{-2} \cdot \mathrm{m}^{6}\right)$ and has to be increased in the optimizing process. According to previous experience from real production in an AAC production facility a compressive strength value of $0.45 \mathrm{MPa}$ can be considered as a limit value necessary to maintain the integrity of the material body and the possibility to manipulate and handle the products.

The standard raw materials used in this AAC technology study are the same as in studies [10] and [17]. Quartz sand has been used as the primary $\mathrm{SiO}_{2}$ source. No fly ash was used in this study. Additionally, high-quality undensified SF (RW Silicium GmbH) was used. The difference between the used SF and the standard one is only the white colour caused by the low content of carbon and silicon carbide. We assume that such a difference has a negligible influence on the hydrothermal reaction mechanism. According to our previous study [17], the optimal surface area of the used $\mathrm{S}$ for achieving the highest $M E$ value was calculated and such an $\mathrm{S}$ was prepared by grinding of raw sand in a ball mill. The calculation of the optimal specific surface area for a volume weight of $120 \mathrm{~kg} \cdot \mathrm{m}^{-3}$ was done by following empirical equation [17]:

$$
\rho=\frac{9586}{s^{0.68}}
$$

where $\rho$ is the target volume weight and $s$ is the optimum surface of sand. This equation was derived for systems containing $30 \%$ replacement of S by SF.

The fineness of $\mathrm{S}$ was controlled by the permeability method according to Blaine. The material description is summarized in Table 2.
Aluminium powder (median particle diameter $25 \mu \mathrm{m}$ ) was used as a foaming agent. Due to non-toxicity and availability, glutamic acid was selected as a foam stabilization admixture in $0.3 \%$ addition to solids. The methodology of the experiment is based on surface area modification of the primary recipe, according to an original industrial recipe characterized by the ratio of active $\mathrm{CaO}$ and $\mathrm{SiO}_{2}(\mathrm{C} / \mathrm{S})$. The recipe is summarized in Table 3. The relatively high content of water assures optimal consistency, which is important for a successful foaming of the mixture.

Table 3. Standard mixture configuration.

\begin{tabular}{cccc}
\hline C/S ratio & $\begin{array}{c}\text { Amount of } \\
\text { foaming } \\
\text { agent }\end{array}$ & $\begin{array}{c}\text { Amount of } \\
\text { stabilization } \\
\text { admixture }\end{array}$ & $\begin{array}{c}\text { Water-solid } \\
\text { ratio }\end{array}$ \\
\hline 0.47 & $0.5 \%$ & $0.3 \%$ & 1.02 \\
\hline
\end{tabular}

The methodological setup is based on the optimization of the mixture characterized in Tables 1 and 3 . The optimization process includes determination of the proper mixing water temperature, water-to-solid coefficient $(w / s)$, amount of foaming agent and increase of $\mathrm{C} / \mathrm{S}$ ratio by the addition of lime to the original recipe. For each sample the quality assessment was performed according to $M E$ and volume weight to reach maximal $M E$ with minimal volume weight.

The compressive strength, volume weight and $M E$ represent the quality evaluation parameters for each sample. The compressive strength $R_{p}$ was analysed by a Zwick Roell Toni Technik device according to ČSN EN 679. The volume weight $\rho$ was determined by weighting of sample bodies with define volume dried at $105^{\circ} \mathrm{C}$ to constant weight according to ČSN EN 678 .

The sample preparation methodology was aimed at simulating the real industrial technology of AAC production. Samples were prepared in moulds of approximately $9 \mathrm{dm}^{3}$ by the following process. All dry components were homogenized and mixed with $75 \%$ of the total amount of mixing water. The remaining $25 \%$ of the total amount of mixing water was used to disperse the aluminium powder. Therefore, the $0.04 \%$ surfactant solution in $25 \%$ of the total amount of mixing water was prepared and used for dispersion of the aluminium powder. The mould, warmed to $50^{\circ} \mathrm{C}$, was filled with

Table 2. Material specification.

\begin{tabular}{lll}
\hline & Specification / producer & Specific surface $\operatorname{area~}\left(\mathrm{m}^{2} \cdot \mathrm{kg}^{-1}\right)$ \\
\hline Quartz sand & Bzenec & 630 (Blaine) \\
Portland cement & CEM I 52.5 R, Mokrá & 520 (Blaine) \\
Quicklime & CL 90, Vitošov & n.a. \\
Gypsum dihydrate & Power Station Chvaletice & n.a. \\
Silica fume & RW Fuller Q1 & 30000 (BET) \\
\hline
\end{tabular}


the mixture and placed for approximately 20 hours into a drying furnace which was set to the temperature of $60^{\circ} \mathrm{C}$. Partially hydrated samples were autoclaved with original prefabricates at the pressure of $1.2 \mathrm{MPa}$. For mechanical analysis two cubes of $100 \mathrm{~mm}$ edge were prepared from autoclaved bodies and dried for 24 hours at $60^{\circ} \mathrm{C}$ to the residual humidity of $4-8 \%$. After the assessment of $R_{p}$ the samples were dried to constant weight and the volume weight $\rho$ was analysed.

For final samples, the phase composition was observed by X-ray Diffraction (X-ray diffractometer Empyrean, PANalytical). The amount of $11 \AA$ tobermorite was determined by TG-EGA with FTIR Spectrometry detection (Q600 + Nicolet IS10, TA Instruments) according to the amount of water released between $110^{\circ} \mathrm{C}$ and $250^{\circ} \mathrm{C}[19]$.

\section{RESULTS AND DISCUSSION}

The influence of mixing water temperature $t_{w}$ was investigated. Figure 1 and Figure 2 show the influence of different mixing water temperature on the properties of AAC samples. It is evident that both observed values are in close correlation. The optimal water mixing

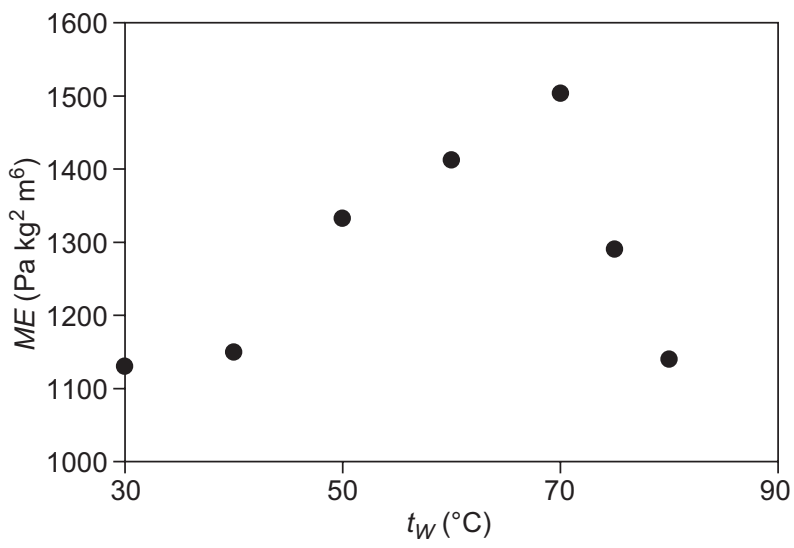

Figure 1. Dependence of ME on mixing water temperature.

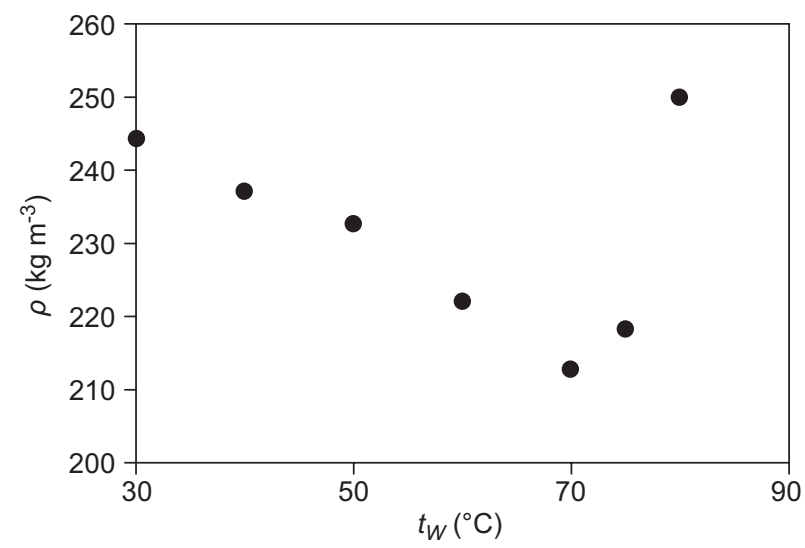

Figure 2. Dependence of volume weight on mixing water temperature. temperature is $70^{\circ} \mathrm{C}$ where minimal $\rho$ and maximal $M E$ were reached. A higher temperature of mixing water has a positive influence on the foaming agent reaction where hydrogen is produced in an optimal rate and in a very short period of time. Above $70^{\circ} \mathrm{C}$ a substantial decrease of $M E$ is observed which is caused by the increasing volume weight. This effect can be attributed to a very rapid reaction of the foaming agent and a strong draft of heated gas which leads to the destruction of non-set pore structure.

The influence of the water-to-solid ratio was investigated with the aim to maintain an optimal consistency of the mixture. According to Figure 3 maximal $M E$ was reached at a water-to-solid ratio of 1.15 . As can be seen on Figure 4 the volume weight decreases with increasing water-to-solid ratio as expected. Unfortunately, samples with higher water-to-solid ratio than 1.15 exhibit lower $M E$. The reason can be found in the pores that are excessively large. These larger pores have a lower capacity to transfer the mechanical stress than smaller ones. For the optimal water-to-solid ratio the consistency was characterized as the time of flow through a Ford Cup according to ČSN EN ISO 2431 with nozzle diameter of $2 \mathrm{~mm}$. The time of flow was equal to $12 \mathrm{~s}$.

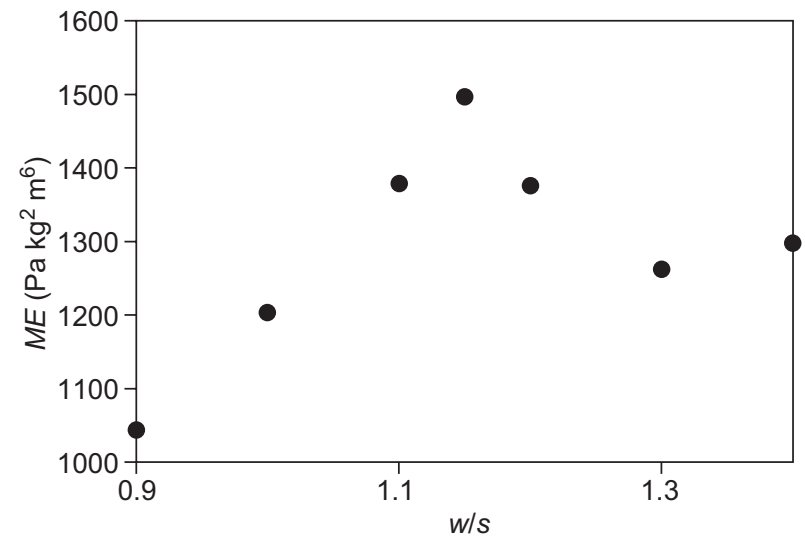

Figure 3. Effect of different water-to-solid ratio, consistency respectively on $\mathrm{ME}$

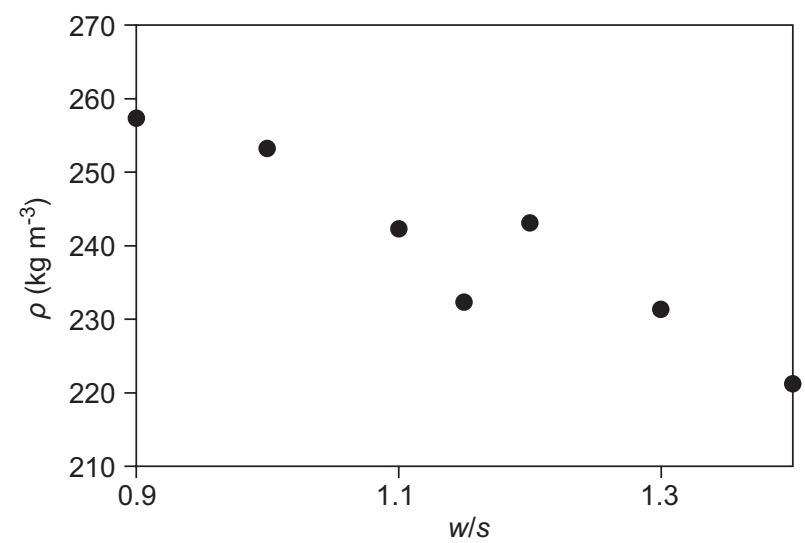

Figure 4. Effect different water-to-solid ratio, consistency respectively on volume weight. 
It is expected that the amount of foaming agent $x$ FA directly influences the total volume of the foamed body. From Figure 5 it is evident that the $M E$ of samples shows a relatively stable character with increasing amount of foaming agent up to $0.4 \%$. With $0.5 \%$ dosage of foaming agent, a rapid decrease of $M E$ is visible. This effect can be explained also by a quite large pore diameter. Gas released due to the foaming agent reaction is normally present in the mixture in the form of small bubbles. With a higher amount of foaming agent, the number of these bubbles increases and thus the distance between them decreases. With shorter distance between the individual bubbles, the probability of and affinity to coalescence is higher. This effect leads to the formation of larger bubbles and larger pores which have lower mechanical stability. Figure 6 shows the dependence of volume weight on increasing amount of foaming agent. As expected, the volume weight decreases with increasing amount of foaming agent. As can be seen, a very low volume weight was reached at $0.4 \%$ amount of foaming agent, where the $M E$ still shows a stable high value. The value of volume weight with $0.5 \%$ of foaming agent has only a slightly lower value. However, the $M E$ is not satisfactory in this case.

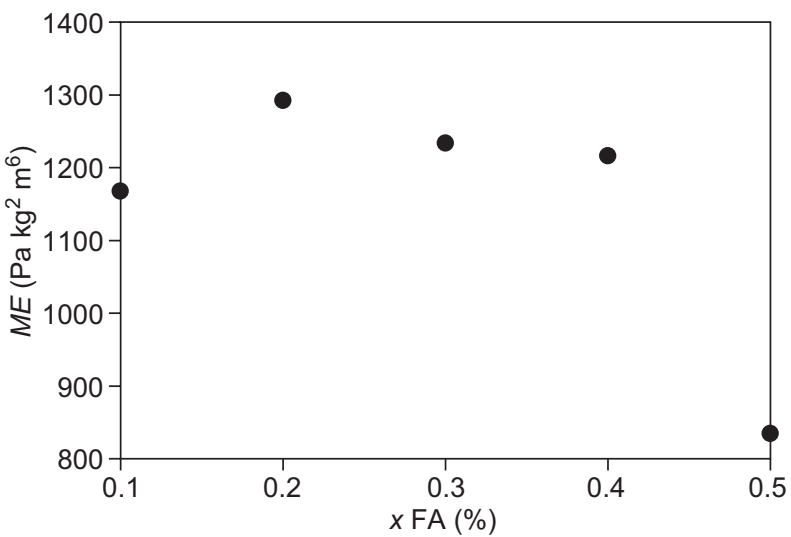

Figure 5. Effect of foaming agent quantity on ME.

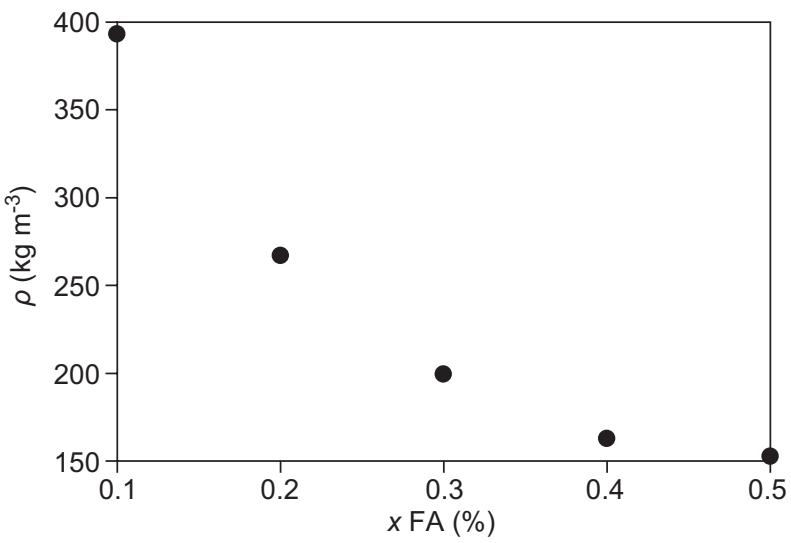

Figure 6. Effect of foaming agent quantity on volume weight.
The mechanical properties of AAC are primarily driven by the amount and morphology of $11 \AA$ tobermorite and the $\mathrm{C} / \mathrm{S}$ ratio. Therefore the dependence of the $M E$ on different $\mathrm{C} / \mathrm{S}$ ratios was investigated. The increase of the $\mathrm{C} / \mathrm{S}$ ratio was realized by addition of lime to the mix. $\mathrm{C} / \mathrm{S}$ ratios corresponding to specific addition of lime can be found in Table 4. From Figure 7 it is evident that the $M E$ increases approximately linear with increasing $\mathrm{C} / \mathrm{S}$ ratio. However for $16 \%$ addition of lime $(\mathrm{C} / \mathrm{S}=$ $=0.629$ ) there is a rapid decrease of $M E$, probably due to overheating of the mixture followed by its destabilization. A similar effect was observed for $12 \%$ addition of lime $(\mathrm{C} / \mathrm{S}=0.576)$, despite of the fact that the $M E$ was at its maximum. Due to the low stability and therefore the high volume weight this sample was not considered further. Due to these facts mentioned above it seems that $10 \%$ is an appropriate addition.

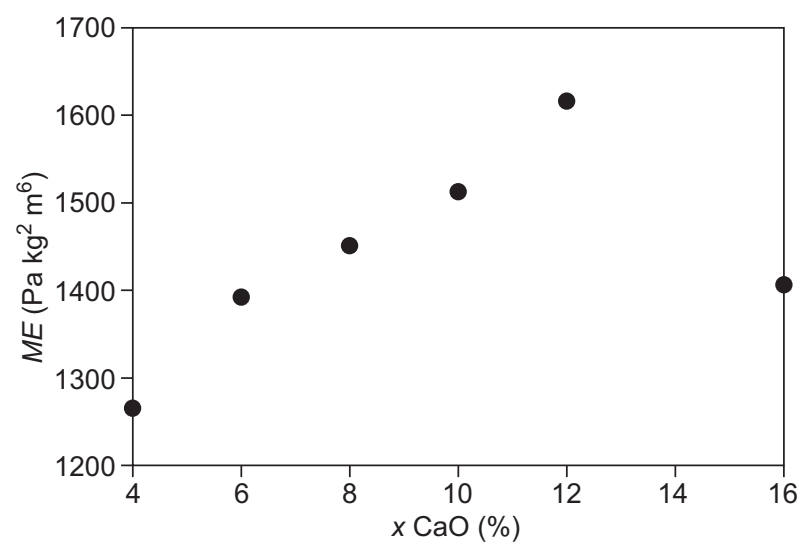

Figure 7. Effect of lime addition on ME.

Table 4. C/S ratios for specific additions of lime.

\begin{tabular}{lcccccc}
\hline$x \mathrm{CaO}[\%]$ & 4 & 6 & 8 & 10 & 12 & 16 \\
\hline $\mathrm{C} / \mathrm{S}$ & 0.470 & 0.497 & 0.523 & 0.550 & 0.576 & 0.629 \\
\hline
\end{tabular}

Based on the results of optimization, two final recipes have been designed. Beside the recipe based strictly on the optimization data, a second type of recipe has been designed where the amount of foaming agent has been set to $0.45 \%$ in order to maintain even lower volume weight. This modification was chosen to explore the behaviour of foaming agent near to its critical amount in the final recipe based on optimization process. The final recipes are summarized in Table 5. The water-tosolid coefficient was set to maintain consistency defined above, with a time of flow of $12 \mathrm{~s}$.

For each recipe four mixes were prepared. From each mix two testing samples were prepared which were submitted to mechanical analysis. As can be seen from Table 6 and Table 7, both recipes reach very high values of $M E$ together with low volume weight around $150 \mathrm{~kg} \cdot \mathrm{m}^{-3}$ and $130 \mathrm{~kg} \cdot \mathrm{m}^{-3}$, respectively, for higher foa- 
Koutný O., Kratochvíl J., Opravil T.

Table 5. Design of final recipes.

\begin{tabular}{cccccccc}
\hline Type & $S_{s}\left[\mathrm{~m}^{2} \cdot \mathrm{kg}^{-1}\right]$ & $\mathrm{SF} / \mathrm{S}$ ratio & Stabilizer dosage $[\%]$ & $x \mathrm{FA}[\%]$ & $x \mathrm{CaO}[\%]$ & $\mathrm{C} / \mathrm{S}$ ratio & tw $\left[{ }^{\circ} \mathrm{C}\right]$ \\
\hline 1 & 630 & 0.3 & 0.3 & 0.40 & 10 & 0.55 & 70 \\
2 & 630 & 0.3 & 0.3 & 0.45 & 10 & 0.55 & 70 \\
\hline
\end{tabular}

ming agent content where the stability of the foam was maintained. The scatter of the results may be attributed to the non-reproducibility of sample preparation which was subordinated to the production line sequence of the AAC facility where the samples were prepared together with original AAC products. Therefore, synchronization with real production was not maintained for each sample. Different pre-setting times and therefore different internal temperatures of samples may cause problems due to thermal shock at the beginning of autoclaving. Thus structure disruption can be expected. Due to this effect the compressive strength is slightly decreased and therefore a lower value of the $M E$ is observed. Optimization of the production sequence should lead to elimination of such an effect and the $M E$ will reache higher values. From visual control it was evident that the structure of samples of type 2 consisted of slightly larger pores (around $2 \mathrm{~mm}$ in diameter) which is relatively close to approximately $1.7 \mathrm{~mm}$ for samples of type 1. Currently there is no other AAC material on the market with such a high value of $M E$.

X-ray diffraction was performed to determine the phase composition, mainly in order to check the presence of phases which could have a negative influence on AAC properties. These phases are mainly xonotlite and portlandite. Results from X-ray diffraction analysis for two randomly selected samples of each recipe are summarized in Table 8 and they show expected phase compositions corresponding to standard AAC. The absence of xonotlite and portlandite was confirmed.

The same samples were submitted to TG-EGA analysis to determine the amount of $11 \AA$ tobermorite. Due to the absence of any other hydrated phases, the amount was determined from the amount of water released in the temperature interval $110-250^{\circ} \mathrm{C}$. Results show that all samples contain similar amounts of $11 \AA$ tobermorite (around $31 \%$ ). This value corresponds to standard AAC products. It can be concluded that mechanical properties are not only determined by the amount of $11 \AA$ tobermorite but also by its morphology. When very fine particles are present in the mix as in our case (silica fume, very finely ground sand) a denser tobermorite structure is formed because the fine particles serve as nucleation centres.

\section{CONCLUSIONS}

A material based on autoclaved aerated concrete (AAC) with low volume weight was prepared. The low volume weight enables not only easy manipulation, but mainly implies a very low heat conductivity. Based on previous studies, the proposed fully-stabilized mixture containing very finely ground sand and silica fume was

Table 6. Properties of samples according recipe No. 1, with $0.4 \%$ dosage of foaming agent.

\begin{tabular}{lccccc}
\hline Sample & F1-1 & F1-2 & F1-3 & F1-4 & Average value \\
\hline$R_{p}[\mathrm{MPa}]$ & 0.68 & 0.72 & 0.71 & 0.79 & $0.725 \pm 0.040$ \\
$\rho\left[\mathrm{kg} \mathrm{m}^{-3}\right]$ & 144 & 151 & 150 & 153 & $149.5 \pm 3.4$ \\
$\mathrm{ME}\left[\mathrm{Pa} \mathrm{kg}^{-2} \mathrm{~m}^{6}\right]$ & 2042 & 1961 & 1953 & 2101 & $2014 \pm 61$ \\
\hline
\end{tabular}

Table 7. Properties of samples according recipe No. 2, with $0.45 \%$ dosage of foaming agent.

\begin{tabular}{lccccc}
\hline Sample & F2-1 & F2-2 & F2-3 & F2-4 & Average value \\
\hline$R_{p}[\mathrm{MPa}]$ & 0.63 & 0.58 & 0.56 & 0.52 & $0.573 \pm 0.040$ \\
$\rho\left[\mathrm{kg} \cdot \mathrm{m}^{-3}\right]$ & 133 & 134 & 132 & 129 & $131.8 \pm 1.8$ \\
$\mathrm{ME}\left[\mathrm{Pa} \cdot \mathrm{kg}^{-2} \cdot \mathrm{m}^{6}\right]$ & 2223 & 2032 & 2005 & 1962 & $2055 \pm 100$ \\
\hline
\end{tabular}

Table 8. Phase composition of randomly selected samples - two samples for each recipe.

\begin{tabular}{lccccccc}
\hline Sample & Quartz & $11 \AA$ Tobermorite & Anhydrite & Katoite & Calcite & Orthoclase & Albite \\
\hline F1-1 & ++++ & ++ & ++ & + & ++ & + & + \\
F1-2 & ++++ & ++ & + & + & + & + & + \\
F2-3 & ++++ & ++ & ++ & + & + & + & + \\
F2-4 & ++++ & ++ & + & + \\
\hline
\end{tabular}

$(++++$ major phase over $50 \% ;+++$ major phase up to $50 \% ;++$ secondary phase $;+$ minor phase $)$ 
optimized to reach very low values of volume weight with sufficient compressive strength (more than $0.45 \mathrm{MPa}$ ). The optimization was performed parallel to the standard production line at an AAC facility to enable easy and fast implementation of the developed recipe into mass production. Two recipes were developed with different amounts of foaming agent. Analysis of samples prepared according these recipes shows very low volume weight around $150 \mathrm{~kg} \cdot \mathrm{m}^{-3}$ for the recipe with $0.4 \%$ dosage of foaming agent and $130 \mathrm{~kg} \cdot \mathrm{m}^{-3}$ for the recipe with $0.45 \%$ dosage of foaming agent. For such a low volume weight, the value of heat conductivity will be close to the value of expanded polystyrene, the main heat-insulating material used in civil engineering. As a result of the compressive strength, the mechanical efficiency reaches very high values more than $2000 \mathrm{~Pa} \cdot \mathrm{kg}^{-2} \cdot \mathrm{m}^{6}$. Currently no commonly produced AAC material has such a high mechanical efficiency. X-ray diffraction and thermal analysis proved that there are no significant differences in phase composition between standard products and our products and the unique mechanical efficiency is caused probably by the denser tobermorite structure which is formed due to presence of very fine particles of silica fume and very finely ground sand, which act as nucleation centres.

\section{Acknowledgement}

This work was financially supported by Materials Research Centre at FCH BUT - Sustainability and Development, REG LO1211, with financial support from National Programme for Sustainability I (Ministry of Education, Youth and Sports).

\section{REFERENCES}

1. Výborný J. (1999). Nauka o materiálech 20 (21): pórobeton 1st. ed. ČVUT, 1999.

2. Chen X., Zhao Z., Hao M., Wang D. (2013): Research of hydrogen generation by the reaction of Al-based materials with water. Journal of Power Sources, 222, 188-195. doi:10.1016/j.jpowsour.2012.08.078.

3. Teng, H., Lee T., Chen Y., Wang H., Cao G. (2012): Effect of $\mathrm{Al}(\mathrm{OH}) 3$ on the hydrogen generation of aluminumwater system. Journal of Power Sources, 219, 16-21. doi:10.1016/j.jpowsour.2012.06.077.

4. Penna A., Mandirola M., Rota M., Magenes G. (2015): Experimental assessment of the in-plane lateral capacity of autoclaved aerated concrete (AAC) masonry walls with flat-truss bed-joint reinforcement. Construction and Building Materials, 82, 155-166. doi:10.1016/j.conbuildmat.2015.02.057.

5. Galvánková L., Másilko J., Solný T., Štěpánková E. (2016): Tobermorite synthesis under hydrothermal conditions. Procedia Engineering, 151, 100-107. doi:10.1016/j. proeng.2016.07.394.

6. Bernstein S., Fehr K.T. (2012): The formation of $1.13 \mathrm{~nm}$ tobermorite under hydrothermal conditions: 1 . The influence of quartz grain size within the system $\mathrm{CaO}-\mathrm{SiO}_{2}-\mathrm{D}_{2} \mathrm{O}$. Progress in Crystal Growth and Characterization of Materials, 58, 84-91. doi:10.1016/j.pcrysgrow.2012.02.006

7. Šauman Z., Hoffmann O. (1981). Závěrečná zpráva: Studium pojivových systémů autoklávovaných stavebních hmot. VUSTAH

8. Svoboda L. (2013). Stavebni hmoty. $3^{\text {rd }}$ ed. Jaga group s.r.o.

9. Škvára F. (1995). Technologie anorganických pojiv I. $1^{\text {st }}$ ed. VŠCHT.

10. Koutný O., Opravil T., Poř́zka J. (2015): Application of metakaolin in autoclaved aerated concrete technology. Advanced Materials Research, 1000, 174-177. doi:10.4028/ www.scientific.net/AMR.1000.174.

11. Vivaldini D.O., Luz A. P., Salvini V. R., Pandolfelli V. C. (2013): Why foams containing colloidal hydrophilic particles are unstable? Ceramics International, 39, 6005-6008. doi:10.1016/j.ceramint.2013.01.007

12. Studart A.R., Gonzenbach U. T., Tervoort E., Gauckler L.J. (2006): Processing routes to macroporous ceramics: A review. Journal of the American Ceramic Society, 89, 1771-1789. doi:10.1111/j.1551-2916.2006.01044.

13. Horozov T.S. (2008): Foams and foam films stabilised by solid particles. Current Opinion in Colloid \& Interface Science, 13, 134-140. doi:10.1016/j.cocis.2007.11.009

14. Kruglyakov P.M., Elaneva S.I., Vilkova N.G. (2011): About mechanism of foam stabilization by solid particles. Advances in Colloid and Interface Science, 165, 108-116. doi:10.1016/j.cis.2011.02.003

15. Juillerat F.K., Gonzenbach U., Gauckler L.J. (2012): Tailoring the hierarchical pore structures in self-setting particlestabilized foams made from calcium aluminate cement. Materials Letters, 70. doi:10.1016/j.matlet.2011.12.006

16. Balsevic R. (1996), Laborbericht 1330: Bildung und Reaktion Sulfathaltigen Phasen. Xella GmbH. Schrobenhausen

17. Koutný O., Opravil T. (2016): The basics of low volume weight aerated autoclaved concrete preparation. Materials Science Forum, 851, 69-74. doi:10.4028/www.scientific. net/MSF.851.69.

18. Shaw S., Henderson C.M.B., Komanschek B.U. (2000): Dehydration/recrystallization mechanisms, energetics, and kinetics of hydrated calcium silicate minerals: an in situ TGA/DSC and synchrotron radiation SAXS/WAXS study. Chemical Geology, 167, 1-2, p. 141-159. doi:10.1016/ S0009-2541(99)00206-5. 